\title{
Did language evolve like the vertebrate eye?
}

\author{
Rudolf P. Botha \\ University of Stellenbosch
}

\section{Introduction}

The vertebrate eye is regularly cited as a classic example of an organ that evolved through natural selection. It is accorded this evolutionary status on the grounds that it exhibits complex design for an adaptive function - that of seeing. Charles Darwin $(1859$, p.79) found the complexity or "perfection" of the eye manifested in "its inimitable contrivances for adjusting the focus of different distances, for admitting different amounts of light, and for the correction of spherical and chromatic aberration"1 . Having defined natural selection as the "preservation of favourable variations and the rejection of injurious variations", Darwin gave three reasons for his belief that the eye evolved through natural selection (he stated these reasons in the form of conditions):

Yet reason tells me that if numerous gradations from a perfect and complex eye to one very imperfect and simple, each grade being useful to its possessor, can be shown to exist; if, further, the eye does vary ever so slightly and the variations be inherited, which is certainly the case, and if any variation or modification in the organ be ever useful to an animal under changing conditions of life, then the difficulty of believing that a perfect and complex eye could be formed by natural selection, though insuperable by our imagination, can hardly be considered real. (Darwin, 1859, p. 79)

In support of each of these three reasons, Darwin adduced considerations which collectively convinced him that "a structure even as perfect as the eye of an eagle might be formed by natural selection" 2 .

It has been contended that human language or some of its features evolved like the vertebrate eye through natural selection ${ }^{3}$. Thus Steven Pinker and Paul Bloom claim that- 
... there is every reason to believe that language has been shaped by natural selection

... [and] that language is no different from other complex abilities such as echolocation or stereopsis, and that the only way to explain the origin of such abilities is through the theory of natural selection. (Pinker and Bloom, 1990, p.708)

These claims are fleshed out by Pinker and Bloom in an account of language evolution which has sparked a robust debate about, amongst other things, the conditions on assigning to language or to features of it the evolutionary status of an adaptation that evolved by natural selection ${ }^{4}$. From the exchanges in this debate, it is clear that these conditions are problematic in being based on questionable assumptions many of which are not stated explicitly. The aim of this paper is to appraise critically the conditions on the basis of which language or features of it have been assigned the status of an adaptation by natural selection. It pursues this aim by closely examining both Pinker and Bloom's selectionist account itself and the debate set off by it. This account deserves such scrutiny: it has been offered as a synthesis of some of the best work on the evolution of language done within a neo-Darwinian framework, and its relative sophistication has drawn favourable comments from supporters and critics alike ${ }^{5}$. No selectionist account of language evolution that compares with Pinker and Bloom's in scope has recently been published. The BBS debate about this account has, in turn, been relatively coherent: thanks to the structured format of the exchanges, it is one of the more highly focused modern debates on issues of language evolution ${ }^{6}$.

\section{The "crux" of the selectionist account}

On Pinker and Bloom's own portrayal, their selectionist account of language evolution is quite simple in regard to what is argued:

All we have argued is that human language, like other specialized biological systems, evolved by natural selection. Our conclusion is based on two facts that we would think would be entirely uncontroversial: Language shows signs of complex design for the communication of propositional structures, and the only explanation for the origin of organs with complex design is the process of natural selection. (Pinker and Bloom, 1990, p.726) 
The argument outlined in this quotation has recently been recast by Bloom in the following format:

(1) - Natural selection is the only explanation for the origin of adaptive complexity.

- Human language shows complex design for the adaptive goal of communication.

- Hence, language has evolved through natural selection. (Bloom, 1998, p. 209)

Before we proceed, a terminological matter requires some clarification: Pinker and Bloom use the expressions complex design, adaptive complexity, complex adaptive design and complex design for an adaptive goal interchangeably for denoting what they take to be one and the same property of entities such as human language or the vertebrate eye.

From the remarks by Pinker and Bloom quoted above and from their (1990, p. 766) assertion that "complex design is indeed the crux of our argument", it may be inferred that there are only two conditions on assigning language the evolutionary status of an adaptation by natural selection:

(2) Language can be accorded the evolutionary status of an adaptation by natural selection-

(a) if it is a specialized biological system, and

(b) if it exhibits complex adaptive design for some evolutionarily significant function.

The seeming simplicity of conditions (2a) and (2b) is, however, deceptive. First, though it does not appear to be the case, (2b) is in fact a compound condition incorporating various more specific conditions each of which involves assumptions that are complex in themselves. Thus each of the constituent concepts of (2b) - "language", "complex adaptive design", "evolutionarily significant function" - has to be constrained in regard to content by one or more specific conditions. Second, (2b) has to be applied in conjunction with a number of 
other general conditions, a fact not reflected in its formulation. Some of these other conditions derive from the theory of natural selection and others from more general considerations of the philosophy of biology. The present paper focuses on the more specific conditions which have to be placed on the constituent concepts of condition (2b); the more general conditions in conjunction with which condition $(2 b)$ has to be applied, and likewise the question of the content of condition (2a) in terms of specifics, call for discussion well beyond the scope of this paper.

\section{3. "(Human) language"}

We consider first the matter of the identity of the linguistic entity or entities to which Pinker and Bloom (1990) refer by means of the expression (human) language, i.e. the entity or entities to which they assign the status of an "adaptation by natural selection". Two questions arise in this regard:

(3a) What is this entity/are these entities?

(3b) Is this an entity/are these entities of a kind that could have the criterial properties of being a specialized biological system [cf. (2a)] and of exhibiting complex adaptive design [cf. (2b)]?

The answers to these questions are not as clear as one would expect them to be. First, Pinker and Bloom loosely use a range of insufficiently well defined expressions - including (human) language and the language faculty - for referring to the entity/entities in question. Second, they operate with a distinction between the language faculty and "parts" of the language faculty that obscures the identity of the entity/entities for whose evolution they propose a selectionist account.

\section{1 "Language" vs. "the language faculty"}

The expression (human) language is but one of a large number of expressions used by Pinker and Bloom for referring to the entity / entities for whose evolution they propose a selectionist 
account. For this purpose, they use a variety of other expressions as well, including the following ones:

- The (human) language faculty

Many people have argued that the evolution of the human language faculty cannot be explained by Darwinian natural selection. (Pinker and Bloom, 1990, p. 707)

But accounting for the evolution of a language faculty permitting restricted variation is only important on the most pessimistic of views. (Pinker and Bloom, 1990, pp. 715716)

In the evolution of the language faculty, many "arbitrary" constraints may have been selected simply because they defined parts of a standardized communicative code. (Pinker and Bloom, 1990, p. 718)

- The language acquisition device

More generally, these considerations suggest that a preference for arbitrariness is built into the language acquisition device at two levels. (Pinker and Bloom, 1990, p. 718)

\section{- Universal grammar}

Does universal grammar in fact show signs of adaptive complexity? (Pinker and Bloom, 1990, p. 773)

\section{- $\operatorname{Grammar}(s)$}

Evolutionary theory offers clear criteria for when a trait should be attributed to natural selection: complex design for some function, and the absence of alternative processes capable of explaining such complexity. Human language meets these criteria: Grammar is a complex mechanism tailored to the transmission of propositional structures through a serial interface. (Pinker and Bloom, 1990, p. 707)

A more serious challenge to the claim that grammars show evidence of good design may come from the diversity of human languages. (Pinker and Bloom, 1990, p. 715) The nature of language makes arbitrariness of grammar itself part of the adaptive solution of communication in principle. (Pinker and Bloom, 1990, p. 718) 
- The cognitive mechanisms underlying language

Do the cognitive mechanisms underlying language show signs of design for some function in the same way that the anatomical structures of the eye show signs of design for the purpose of vision? (Pinker and Bloom, 1990, p. 712)

- The computational mechanisms underlying the psychology of language

Our own arguments spring from the adaptive complexity of the computational mechanisms underlying the psychology of language as it is currently understood. (Pinker and Bloom, 1990, p. 766)

\section{- $\quad$ The ability to use a natural language}

This list of facts ... suggests that the ability to use a natural language belongs more to the study of human biology than human culture. (Pinker and Bloom, 1990, p. 707)

Pinker and Bloom refrain from stating explicitly whether they use the expressions (human) language, the (human) language faculty, the language acquisition device, universal grammar, grammar(s), the cognitive mechanisms underlying language, the computational mechanisms underlying the psychology of language and the ability to use natural language for referring to the same or different entities ${ }^{7}$. Particularly problematic in this regard, is the way in which they use the expressions language and the language faculty. In some statements they obviously use these expressions for referring to the same entity - for example, when they state that [italics added - RPB]-

In the evolution of the language faculty, many "arbitrary" constraints may have been selected simply because they defined parts of a standardized communicative code in the brains of some critical mass of speakers. Piattelli-Palmarini may be right in claiming that there is nothing adaptive about forming yes-no questions by inverting the subject and auxiliary as opposed to reversing the order of words in the sentence. But given that language must do one or the other, it is highly adaptive for each member of a community of speakers to be forced to learn to do it the same way as all the other members. (Pinker and Bloom, 1990, p.718) 
In other statements, however, the expressions the language faculty and language are clearly intended to refer to different entities. The following is a case in point:

Moreover, a genetic change in the language faculty need not simply generate the ambient language verbatim in which case ease of processing would be the only selection pressure, and further evolution would halt. It can generate a superset of the language (or a partially overlapping set), much the way contemporary children go beyond the information given the development of creoles, sign languages, and their frequent creative invention. If such creations increased expressive power and were comprehendable by others by any means, it could set the stage for the next iteration of the evolution process. (Pinker and Bloom, 1990, p.776)

Pinker and Bloom, incidentally, not only omit to clarify their distinction between language and the language faculty; they also fail to make clear whether the expressions the language and the ambient language differ in regard to ontological import.

In the BBS discussion, various commentators have expressed serious misgivings about the way in which Pinker and Bloom use the expressions language and the language faculty for identifying the entity or entities whose evolution is at issue. They are criticized, for example, by Dan Sperber (1990, pp. 756-757) and Anat Ninio (1990, p. 746) for not drawing a proper distinction between "language" and "the language faculty" and, consequently, for confusing the respective evolutions of these entities.

Interestingly, Pinker and Bloom (1990, pp. 776-777) have rejected these criticisms, claiming that in their selectionist account of language evolution "there are no paradoxes, or confusions between language and the language faculty". This response is revealing in the sense that Pinker and Bloom do not argue that the distinction between "language" and "the language faculty" invoked by Sperber and Ninio is purely terminological, or obscure, or flawed in some other way. Moreover, Pinker and Bloom seem to agree that "language" and "the language faculty" can indeed be confused as entities whose evolution is at issue. They fail, however, to make clear in what way "language" and "the language faculty" (could have) evolved separately from each other and whether there is any distinct domain of fact about the 
evolution of "language" which is not a domain of fact about the evolution of the "language faculty" as well. And, crucially, Pinker and Bloom do not consider the question whether "language", as an entity that is distinct from "the language faculty", satisfies conditions (2a) and (2b). That is, they do not consider the question whether "language", as such a distinct entity, could be a specialized biological system and could show signs of complex design ${ }^{8}$. All accounts that accord "language", as an entity distinct from "the language faculty", the evolutionary status of "adaptation by natural selection" have to show that it represents a kind of entity that could have these properties.

To resolve the problem of identifying the entity/entities for whose evolution Pinker and Bloom offer their selectionist account, it may be assumed that it is the entity standardly portrayed in generative linguistics as the initial state of the language faculty. And that their use of the expression (human) language represents a form of terminological variation that has no ontological significance. The initial state of the language faculty represents in Chomsky's view an individual's innate knowledge of language as it is embodied in a biologically based system of genetically encoded linguistic principles, which are collectively referred to as $U$ (niversal) $G$ (rammar $)^{9}$. In terms of this characterization, the initial state of the language faculty could have some of the properties - a biological basis and a genetic component alluded to in conditions (2a) and (2b). Pinker and Bloom (1990, pp. 713-714) accept the idea of a U(niversal) G(rammar) and, moreover, argue that specific individual characteristics - or "parts", "components", or "mechanisms" - of UG make a contribution to the evolutionarily significant communicative function for which "language" evolved. Thereby they obscure in a second way the identity of the entity or entities for the evolution of which they offer a selectionist account, as will be shown directly below.

\section{2 "The language faculty" vs. "parts of the language faculty"}

In his commentary on Pinker and Bloom's target article, Elliot Sober (1990, p.746) draws a distinction between a compound entity or "complex phenotype" considered as a "univocal object" and the "specific features" or "characteristics" of such an entity. This is an important distinction from the point of view of giving an account of the object's evolution, as Sober 
(1990, p. 764) explains with reference to the object known as the "human birth canal". In Sober's view:

It is a waste of time to wonder whether "the human birth canal" is the product of natural selection. Rather, one wants to focus on specific features that the canal possesses. Some may be adaptive; others not. Presumably, we would want to tell quite different stories and to muster quite different kinds of evidence when we replace a single phenotype with a set of more finely individuated phenotypes. (Sober, 1990, p. 764)

Sober maintains that the distinction between a complex phenotype taken as a univocal object and the specific characteristics of such a phenotype is applicable to the language faculty. And he observes that Pinker and Bloom do recognize the need to distinguish some "features" of the language faculty from others. Thus they $(1990$, p. 718) maintain, for example, that "even if it could be shown that one part of language has no function, that would not mean that all parts of language had no function."

In their response to Sober's comments, however, Pinker and Bloom (1990, pp. 765-766), do not take up his point that from an evolutionary perspective a distinction should be drawn between (the) language (faculty) as a univocal object and specific "parts" or "features" of it. ${ }^{10}$ Nor do they take up his point that a selectionist account should be given for specific features rather than the whole. Instead, Pinker and Bloom switch back and forth, in what seems to be a non-deliberate way, between talking about the evolution of specific parts or features of the language faculty and talking about the evolution of (the) language (faculty) as a univocal object. About the evolution of features, they make such general statements as the following:

In the evolution of the language faculty, many arbitrary constraints may have been selected simply because they defined parts of a standardized communicative code ... (Pinker and Bloom, 1990, p. 718)

And about the evolution of the univocal object, Pinker and Bloom say things in the following vein [emphases added - RPB]: 
The way to explain the evolution of language may not be to look for some climatic or ecological condition to which it was a direct selective response. (Pinker and Bloom, 1990, p.773)

The general question of how the evolution of the language faculty as a univocal object is related to the evolution of the specific parts of the language faculty is not considered by Pinker and Bloom. This question can be broken down into ones that are more specific. For example: If fundamental parts of the language faculty are believed not to have evolved by natural selection, how could it be maintained that the faculty as a whole evolved by natural selection? And: What are the conditions on assigning the evolutionary status of "adaptation by natural selection" to an individual part of the language faculty? Specifically: How could conditions (2a) and (2b) apply or be made to apply to specific parts of the language faculty? That is: In what non-ad hoc sense could it be maintained that a specific part of the language faculty is a "specialized biological system" or that it exhibits "complex adaptive design"? To these and related other questions we will return in Section 5 below.

It is time to conclude this section. It has dealt with the question of the constraints on the concept of "(human) language" as that concept is used in the selectionist conditions (2a) and (2b). That concept, as used by Pinker and Bloom, was found to be less than well constrained. It fails to provide a basis for distinguishing in a non-arbitrary way between language and the language faculty. It fails to provide a basis for distinguishing between the language faculty as a univocal object and specific features or parts of the language faculty. These failures,

evidently, leave a considerable amount of fuzziness in the scope within which conditions (2a) and (2b) could be properly applied.

\section{4. "Evolutionarily significant function"}

Selectionist condition (2b) incorporates two requirements, the first of which is that language has to serve an evolutionarily significant function. The second, related, requirement is that language has to exhibit complex adaptive design (for that function). In the present section, the first of the two requirements, as it features in Pinker and Bloom's selectionist account, is 
considered from the perspective of some of the constraints that need to be placed on their concept of "function". The guiding question will be whether these constraints are sufficiently well articulated to distinguish in a non-arbitrary way among the various kinds of aberrant functionality of parts of language.

Pinker and Bloom assign to both language as a whole and specific parts or features of language a function which they claim to be significant from an evolutionary point of view. As for language as a whole, according to them (1990, pp. 712-720, 726, 763, 767), it shows signs of complex design for carrying out a function that is "reproductively significant". This function they (1990, p. 712) characterize as that of "communicating propositional structures over a serial channel". In less formal terms, Pinker and Bloom (1990, p. 766) alternatively describe it as the function of "mapping meanings onto pronounceable and recoverable sounds". On their (1990, p. 712) view, this function is reproductively significant in the sense that it allows humans to acquire and exchange information. Exchanging information makes it possible for humans to deal with causal contingencies of the environment as these change within a lifetime. This, Pinker and Bloom (1990, p. 712) claim, provides humans with a decisive advantage in competition with other species, which can only defend themselves against new threats in evolutionary time. The advantage of being able to acquire information about the world second-hand from the reservoir of knowledge accumulated by other individuals is that "one can avoid having to duplicate the possibly time-consuming and dangerous trial-and-error process that won that knowledge". Moreover, Pinker and Bloom (1990, p. 712) observe, the internal states of cooperating individuals within the same group are amongst "the most significant things in the world worth knowing about". The communication of knowledge and internal states useful for surviving and reproducing, thus, is on Pinker and Bloom's view the function central to the evolution of language that "shaped" language in the human species. ${ }^{11}$

Turning to the functions of the parts of language, Pinker and Bloom (1990, p. 713) maintain that language fulfils its general communicative function in virtue of being "a complex system of many parts tailored to mapping a characteristic kind of semantic or pragmatic function onto a characteristic kind of symbol sequence". The parts in question are substantive (linguistic) universals, also called by them "the building blocks of grammar that all theories of universal 
grammar posit". Pinker and Bloom's (1990, pp. 713-714) list of substantive linguistic universals and their presumed functions includes, for example:

(4a) lexical categories - such as noun, verb, adjective and preposition - whose function is to distinguish basic ontological categories such as things, events and states, and qualities. major phrasal categories - such as noun phrase, verb phrase and so on - whose function is to describe particular things, events, states, locations and properties.

(4c) verb affixes whose function is to signal the temporal distribution of the event that the verb refers to (aspect) and the time of the event (tense).

(4d) pronouns and other anaphoric elements whose function is to convey patterns of coreference among participants in complex relations without the necessity of repeating lengthy definite descriptions.

What Pinker and Bloom do is to divide or anatomize the function of language - or the "language function", as it is also called - into subfunctions and to associate specific subfunctions with individual substantive universals. These universals are functional to the extent that they play a role in the mapping of propositional structures on to a serial channel. ${ }^{12}$

Central to the concept of function as a component of selectionist condition (2b), then, is Pinker and Bloom's assumption that the individual parts of language should have matching (sub)functions. As argued by various BBS commentators, however, the fit between those parts - also referred to as "linguistic forms", "structures" or "features" - deviates from what is to be expected on Pinker and Bloom's selectionist view of language evolution. Below we consider various kinds of deviation or "misfit" and the way in which they bear on the adequacy of selectionist condition (2b).

\section{1 "Dysfunctionality"}

Dysfunctionality represents a first kind of form-function fit that is problematic within the context of condition (2b). A formal feature of language is considered dysfunctional if it has some function but does not fulfil this function particularly well. An instance of a 
dysfunctional feature, on Piattelli-Palmarini's (1990, p. 750) analysis, is the formal feature of tenses. It serves the function of expressing temporality, but does this less than well. For example, Piattelli-Palmarini (1990, p. 753) observes, the "resources of tenses" do not allow us to express the simultaneity of two events by syntactic means alone if that simultaneity occurs at a time that lies in the future with respect to the time of utterance. On his analysis, we have to use some "elaborate, strained, prolix periphrasis, supplemented with lexical pointers". ${ }^{13}$

Piattelli-Palmarini uses the dysfunctionality of tenses as the basis for stating a general "challenge" to Pinker and Bloom's selectionist account of the evolution of language:

How inadequate (how dysfunctional) must a structure be before an adaptationist admits that it cannot have been shaped by the proposed function? How does adaptive underdetermination differ from the claim that the structure is only compatible with the function? (Piattelli-Palmarini, 1990, p. 753)

Pinker and Bloom's direct response to this challenge by Piattelli-Palmarini is to turn his question around:

How adequate (how functional) must a structure be before an antiadaptationist admits it was shaped by the proposed function? (Pinker and Bloom, 1990, p. 773)

This response, though it might score points in a debate, does not address the substance of Piattelli-Palmarini's questions. It is therefore not surprising that Pinker and Bloom (1990, p. 773) offer a second, more principled, response to Piattelli-Palmarini's challenge. They maintain that the criterion demanded by Piattelli-Palmarini is not whether there are some things that grammar cannot do (well), but whether there are things it can do "that cannot be done by a system designed at random". By "at random" they mean "unrelated to the task that the system is to be used for". They illustrate their point by posing two questions. Their first question is about a computational system that is either assembled at random or designed for some specific, but randomly selected, task: 
Would it [this computational system - RPB] be capable, without modification, of encoding into strings of words the tense distinctions that human language can express? (Pinker and Bloom, 1990, p. 773)

Their second question is about random neural spandrels: ${ }^{14}$

What does an arbitrary cell adhesion molecule know about computational systems that can encode tense distinctions (as opposed to building feathers) - unless it is nonarbitrary because it had been selected to build a system that can do so? (Pinker and Bloom, 1990, p. 773)

Central to this line of argument is the replacement of one criterion of functionality by another which, in the short run, shields Pinker and Bloom's selectionist account from criticisms based on the alleged dysfunctionality of elements of linguistic form. To show, however, that the threat posed by such dysfunctional elements is not a real one, it would have to be argued that Pinker and Bloom's substitution of one criterion of functionality for another is justified on principled grounds. Of course the argument, if successful, would turn the substitution into more than merely an evasive stratagem. No such argument has been presented by Pinker and Bloom.

\section{2 "Non-uniqueness", "nonspecificity"}

The non-unique or nonspecific way in which specific linguistic forms are associated with specific functions represents a second kind of form-function fit that has been considered a problem for selectionist condition (2b). Thus, in the BBS debate Piattelli-Palmarini (1990, p. 753) has observed that according to Pinker and Bloom one of the central communicative functions of language is to enable speakers to establish and manage social relations. Universal grammar, in Pinker and Bloom's view, has been significantly shaped by the need to promise, instruct, threaten, persuade, order and so on. Piattelli-Palmarini accordingly finds it a puzzle that- 
Although there are syntactic constructions especially suited to these situations (modals, hypotheticals, conditionals, and so forth), this "function" does not uniquely pick out any syntactic construction or module. (Piattelli-Palmarini, 1990, pp. 753754)

He observes that there are "endless ways" to promise, threaten, induce and so on. Conditionalization and contract-making, likewise, "map onto a desperately mixed syntactic bunch". The phrasing of bona fide contracts, according to Piattelli-Palmarini, is exhausting and frustrating. Ordinary speakers, he contends, feel "that they can be fooled in a thousand ways, by the mere wording of contracts". All this then, in his opinion, goes to show that UG is "a very bad device for cheater detection". And so he draws the general conclusion that-

The function explains next to nothing of the structure that it has allegedly shaped through natural selection. (Piattelli-Palmarini, 1990, p. 754)

This conclusion is seen by Piattelli-Palmarini as "refuting" Pinker and Bloom's selectionist account, "or at least weakening [it] substantially". What seems "vastly more plausible" to Piattelli-Palmarini is that, possessing the languages we happen to possess, we human beings have "managed somehow to coax them into the uses we see fit, getting plenty of glitches ... as a result".

Pinker and Bloom's (1990, p. 773) response to Piattelli-Palmarini's criticism based on the nonuniqueness of the link between specific forms and specific functions is cryptic in the extreme:

Piattelli-Palmarini's demand that there be a unique pairing of syntactic constructions with social functions (e.g., a construction for cheater detection) is not reasonable; see our response to Hornstein. (Pinker and Bloom, 1990, p. 773)

To see what it is that makes Piattelli-Palmarini's demand "not reasonable" we will have to consider, first, Hornstein's critique of Pinker and Bloom's selectionist account and, then, their response to that critique. 
One of Hornstein's (1990, pp. 735-736) criticisms of Pinker and Bloom's selectionist account is that it does not offer an evolutionary model for the selection of specific grammatical properties. Such a model, in Hornstein's view, should for example answer the question: "What evolutionary pressure selects for the case filter or structure dependence or the binding theory or X' [= X-bar, RPB] theory?" Hornstein (1990, p. 736) contends that a perfectly serviceable communication system that did not mark "abstract" case on NPs could be just as good a medium of communication as one that did. And he comes to the conclusion that-

In fact, despite Pinker and Bloom's sensitivity to providing "just-so" stories ... that is indeed all they provide. They do not begin to offer even the outlines of an account of what specific environmental pressures specific grammatical properties are responses to, let alone evidence that these pressures were actually impinging on our ancestors. Nor do they suggest what sorts of tradeoffs might have led to natural selection choosing some specific principle of grammar. Until this is done, however, very little has been accomplished by way of evolutionarily explaining these properties. (Hornstein, 1990, p. 736)

If Pinker and Bloom wish to show that the complex properties of language are due to the "workings of natural selection", Hornstein stresses, nothing less will do than their spelling out the environmental pressures that would cause specific grammatical properties / principles to be selected. But, he points out, "Pinker and Bloom never provide a single detailed discussion of this type for a grammatical principle".

Pinker and Bloom respond to this criticism of Hornstein's by presenting an argument from analogy. First, they state that-

Demanding to know what environmental pressure selected for X-bar theory is like demanding to know what environmental pressure selected for the third metacarpal or the right iris. (Pinker and Bloom, 1990, p. 772)

By implication, they are saying that this demand would be "not reasonable". But this line of argument requires that, as a component of language, X-bar theory should have approximately 
the same status as the third metacarpal has as a part of the anatomy of the hand or the right iris has as a part of the anatomy of the eye. It is not evident that this is the case, nor do Pinker and Bloom show that it is.

Second, Pinker and Bloom maintain that-

Natural selection is not a list of environmental forces each tugging at its own bit of anatomy. (Pinker and Bloom, 1990, p. 772)

Elaborating on this point, Pinker and Bloom observe that acute vision depends on several factors: a controllable iris, transparent vitreous humour, a focusing lens, a densely packed fovea all contribute to acute vision. Vision they portray, moreover, as a general function: vision is adaptive across a wide range of environments. It would be a mistake therefore, they claim, to assign each of these a different environmental pressure.

Third, to clinch the argument, Pinker and Bloom state that-

Likewise, the value of each component of universal grammar is its contribution to how the entire language faculty allows complex thoughts to be communicated, an ability that is useful across a huge range of environments. (Pinker and Bloom, 1990, p. 772)

The acceptability of Pinker and Bloom's second and third points depends on the tenability of what they assume about the way in which parts of a structure - as opposed to the structure as a whole - are or are not shaped by specific environmental pressures.

The question, ultimately, is whether the requirement of complex adaptive design expressed in selectionist condition (2b) should (be made to) apply to components of a structure as well. And, if so, in what non-arbitrary form? These questions, regrettably, are not explicitly addressed by Pinker and Bloom — a point to which we will return in Section 5 below. 


\section{3 "Functionlessness"}

In the case of dysfunctionality, a given form can be assigned some (discernible) function. In the case of functionlessness, however, it is not possible to assign the form any function that could explain its existence in selectionist terms.

Several of Pinker and Bloom's critics have argued that certain features or formal building blocks of language are functionless. A case in point, cited by Hornstein (1990, p. 735) in the BBS debate, is (the principle of) structure-dependency. ${ }^{15}$ Languages universally use structure-dependent rules; yet, structure-dependency does not seem to serve any function which is significant from the perspective of natural selection. Thus, Noam Chomsky (1988, pp. 46-47) - who first made the point about the functionlessness of structure-dependency has repeatedly observed that structure-dependent rules are more complex, and consequently less highly valued, than structure-independent rules. Chomsky believes that a language using simpler, structure-independent, rules would be quite easy to construct. Such a language, in his view, would "function perfectly well for purposes of communication, expression of thought, or other uses of language". This means that in Chomsky's view structuredependency, as a formal building block of language, is not required by the functions or uses of language. In turn, this means that on Pinker and Bloom's selectionist account of the evolution of language it is a mystery why language should have the property of structuredependency.

In their target article, Pinker and Bloom anticipate some of the threat posed by the functionlessness of certain formal properties of language and take certain steps to defuse it. First, they observe that-

In their crudest form, arguments about the putative functionlessness of grammar run as follows: "I bet you can't tell me a function for Constraint $\mathrm{X}$, therefore language is a spandrel". But even if it could be shown that one part of language had no function, that would not mean that all parts of language had no function. (Pinker and Bloom, 1970, p. 717) 
This response of Pinker and Bloom's falls short, however, of addressing the threat which structure-dependency poses to their selectionist account. The functionlessness of structuredependency is not taken to indicate that "all parts of language have no function". The point, rather, is that structure-dependency is such a fundamental formal feature of language that, on any selectionist account of the evolution of language, one would expect it to have a function of the kind under consideration.

Second, Pinker and Bloom (1990, p. 717) suggest that what is taken to be a part of the language faculty may appear to be functionless since it "may not be a genuine part of the language faculty but just a description of one aspect of it ...". Thus, they (1990, p. 717) observe that "the recent history of linguistics provides numerous examples where a newly discovered constraint is first proposed as an explicit statement listed as part of the grammar, but is then shown to be a deductive consequence of a much wider ranging principle". They illustrate this point with reference to a filter ruling out [NP-to-VP] sequences (e.g. John to have won is surprising): at first it was proposed that these sequences were ruled out by a filter peculiar to English; today, the ungrammaticality of such sequences is seen as a consequence of the Case Filter, a linguistic universal. ${ }^{16}$

Structure-dependency would, of course, have to be shown to be in fact an instance of the kind of constraint just noted. This is unlikely to be easy to do, however, for at least two reasons. On the one hand, unlike the above-mentioned filter, structure-dependency is one of the most fundamental formal features of language. On the other hand, as a fundamental feature of language, structure-dependency has proved to be relatively theory-neutral. Chomsky's theory of linguistic form has undergone numerous revisions - some quite radical - over the years; yet structure-dependency has retained the status of a fundamental property of language. In short, it would seem that structure-dependency remains an embarrassing formal feature from the perspective of selectionist condition $(2 b)$.

\section{4 "Arbitrariness"}

Pinker and Bloom's treatment of what may be problems of form-function fit within the framework of selectionist condition $(2 b)$ is less than adequate since they omit to draw certain 
fundamental conceptual distinctions in any explicit way. Specifically, instead of distinguishing in some deliberate way between dysfunctionality, non-uniqueness and functionlessness, they lump these together under the heading of "arbitrariness". As a consequence, they do not explicitly consider the question of whether all these kinds of formfunction "misfit" are equally problematic from the perspective of selectionist condition (2b).

Particularly troublesome is the way in which functionlessness - Pinker and Bloom refer to it as "nonfunctionality" - and arbitrariness are interrelated. Pinker and Bloom consider features of language to be arbitrary if-

(5a) they are "not completely predictable" or cannot be "explained" in terms of an adaptive function (Pinker and Bloom, 1990, p. 716);

(5b) there is "nothing necessary about them" (Pinker and Bloom, 1990, p. 717);

(5c) they "could have been different" (Pinker and Bloom, 1990, p. 718);

(5d) they are "nonoptimal" or if "there are alternative solutions that are better from the standpoint of some single criterion" (Pinker and Bloom, 1990, p. 717).

Clearly, the senses of "arbitrariness" alluded to in (5a)-(5d) do not include a single one on which arbitrariness equals functionlessness: for a formal feature or structure to have no (communicative) function, obviously, is not the same as for a feature or structure to have a function that is "unpredictable" (5a), "inexplicable" (5a) or "nonnecessary" (5b), or for a feature or structure to serve a particular function in a nonoptimal way (5d). This means, then, that Pinker and Bloom cannot account for the functionlessness of features of language automatically, by mere appeal to considerations that can be used in explaining the arbitrariness of features. Their discussion of functionlessness / arbitrariness shows no awareness of this point, however, a fact that contributes to the conceptual fuzziness of selectionist condition ( $2 b)$.

It has been the main finding of this Section 4 that the concept of "function" in terms of which selectionist condition ( $2 \mathrm{~b}$ ) is stated is less than well constrained. In particular, it conflates a number of distinctions that have to be drawn among such different kinds of form-function "misfit" as dysfunctionality, nonuniqueness / nonspecificity and functionlessness. These kinds 
of form-function "misfit" are lumped together in Pinker and Bloom's concept of "arbitrariness". As a consequence, the functionality requirement incorporated in selectionist condition (2b) cannot be applied in a non-arbitrary way to individual parts or features of language whose functionality appears to be problematic.

\section{5. "Complex adaptive design"}

In terms of the second requirement included in selectionist condition (2b), language has to show signs of complex adaptive design in order to qualify for the evolutionary status of "having evolved by natural selection". But under what circumstances could language be considered to meet this requirement? To what extent is this a compound requirement, made up of less complex requirements for assigning entities the respective atomic properties of "being complex", "being adaptive" and "exhibiting design"? And is it possible for language as a whole and for individual parts or features of language to manifest complex adaptive design in one and the same way? That is, does it make sense to adopt a single, general requirement, which has to apply to both language as a univocal object and individual parts or features of language? The present section pursues these questions by analysing the concepts of "design", "complexity" and "adaptivity" that are central to Pinker and Bloom's selectionist account of language evolution. The aim of the analysis is to determine whether these concepts are sufficiently well constrained in content (as was done above for the concepts of "language" and "evolutionarily significant function").

\section{1 "Design"}

Pinker and Bloom attribute design both to language as a whole and to (the) specific parts of language. Specifically, they claim that-

(6a) Language shows signs of design for a communicative or mapping function. (cf. Pinker and Bloom, 1990, pp. 712, 726, 766, 767).

(6b) Each of the many parts of language is tailored to the mapping function it serves. (cf. Pinker and Bloom, 1990, p. 713). 
Claims (6a) and (6b) differ in content from claims (7a) and (7b), respectively.

(7a) Language has a communicative or mapping function.

(7b) Each of the many parts of language has a mapping function

With reference to the parts of language referred to in (4a) above, claim (7b) can be fleshed out as (8a), which differs significantly in content from claim (8b):

(8a) The function of the major lexical categories noun, verb and adjective is to distinguish basic ontological categories such as things, events or states, and qualities.

(8b) The major lexical categories of noun, verb and adjective are tailored to distinguish basic ontological categories such as things, events or states, and qualities.

Function claims such as (8a) differ in content from design claims such as (8b) in the following general way: something can serve a function without having been designed for it. Or, conversely, something could have been designed for a function, yet fail to serve it. These observations do not hold at a conceptual level only, but apply to biological function and natural design as well. This is shown by Allen and Bekoff, who observe that-

Function ... is neutral with respect to the phylogenetic pathway by which a trait acquires a function. (Allen and Bekoff, 1995, p. 617)

They point out, moreover, that-

A trait may have a biological function but not be naturally designed for that function (although it may be a product of natural design for some other function). (Allen and Bekoff, 1995, p. 617) 
These considerations imply that showing that a particular trait was designed for a particular function requires more than showing that it serves that function. As Allen and Bekoff (1995, p. 617) put it, "showing design is more difficult than showing function" ${ }^{17}$.

Pinker and Bloom do not in any explicit and non-ad hoc way draw a distinction between function claims such as (8a) and design claims such as (8b). And they seem to lack the conceptual basis needed for this. They do offer certain observations by Boorse and Cummins in an attempt to "characterize what is behind intuitions of design" of objects as wholes. Thus, according to Pinker and Bloom,-

The key features seem to be (1) a constant but heterogeneous structure: The parts or aspects of an object are unpredictably different from one another; (2) a unity of function: The different parts are organized so as to cause the system to achieve or maintain some special effect - special because it is improbable for systems lacking that organization that are otherwise physically similar to it, and special because it is among the small set of states that we would antecedently recognize as beneficial to someone or something. (Pinker and Bloom, 1990, p. 767)

Pinker and Bloom's chosen characterization of the intuitions behind the design of objects as wholes does not, however, carry over to intuitions behind the tailoring of parts of objects. Clearly, the test of structural heterogeneity coupled with functional unity cannot be applied to a part of a whole: to do this would be to treat the part as if it were a whole. Pinker and Bloom offer nothing that serves as a clarification of the sense in which individual parts of language could be said to be tailored to their specific function(s). They lack an explicitly articulated and well-constrained concept of "the tailoring of a part of language" which is distinct from the concept of "the function of a part of language". This makes it impossible to apply the requirement of (complex adaptive) design - as a component of selectionist condition (2b) to parts of language. 


\section{2 "Adaptive complexity"}

Pinker and Bloom collapse the concepts of "complexity" and "adaptivity" into that of "adaptive complexity" which, on their view,-

describes any system composed of many interacting parts where the details of the parts' structure and arrangement suggest design to fulfil some function. (Pinker and Bloom, 1990, p. 709) ${ }^{18}$

Both in the BBS debate and elsewhere it has been argued that Pinker and Bloom's compound concept of "adaptive complexity" is flawed in that it is not sensitive to certain fundamental distinctions, to which we next turn.

A first distinction is that among different sources of complexity. In this connection Pesetsky and Block (1990, p. 751) point out that Pinker and Bloom allow for aspects of language not to be explained as adaptations "but as arbitrary features that are present because fixing on some communication protocol had an evolutionary advantage, even if there might have been far better alternatives". If arbitrariness characterizes language in a substantial way, a "serious problem" arises in Pesetsky and Block's (1990, p. 751) view: "How do Pinker and Bloom know that the arbitrary choices of which they speak don't increase complexity?" Pesetsky and Block illustrate the point of this question with reference to the evolution of the locomotion of a crablike creature:

Suppose that in the evolution of a crablike creature, a change in environment creates a situation in which survival requires faster locomotion. There are many alterations that an engineer might think of, but evolution favours a quick and dirty approach. Thus, a mutant appears that does the trick by putting together already present behavioral patterns into an utterly shambolic combination of rolling, pushing, flipping, and sliding. If this arbitrary combination is preserved, it can lead to further complexities in later evolutionary change, some of which might themselves be adaptive, others not. (Pesetsky and Block, 1990, p. 751) 
The application to language is "obvious" to Pesetsky and Block: the principle of parity plus the need for arbitrariness can result in the choice of "chimerical features of language that inculcate chimerical additions and encrustations down the road". ${ }^{19}$ As noted above, the crucial question to them is "How much of the complexity that we see in language is there because of the needs of complex functional design, and how much is a by-product of arbitrary choices?" Pesetsky and Block proceed to argue that much of the complexity of language is a by-product of arbitrary choices, a conclusion which weakens Pinker and Bloom's selectionist view of linguistic complexity. The cause of the weakness here is that Pinker and Bloom have not made their concept of linguistic complexity sensitive to distinct sources of complexity. As a result, they are in effect conflating the complexity that arises from design (or adaptive complexity) and the complexity that arises from arbitrary choices (or arbitrary complexity). This introduces a considerable measure of arbitrariness in assigning language or parts of language the property of being adaptively complex within the framework of selectionist condition (2b). Pinker and Bloom, significantly, do not respond in a direct way to Pesetsky and Block's criticisms of their insufficiently well articulated concept of "complexity".

A second distinction to which Pinker and Bloom's concept of "adaptive complexity" is not sensitive is pointed out in the BBS debate by Lewontin:

Pinker and Bloom's biological mistake is that it is not the complexity of language or its organs that is at issue, but the increase in complexity from the ancestral state. (Lewontin, 1990, p. 740)

To flesh out his point, Lewontin (1990, p. 740) observes that Broca's and Wernicke's areas were recruited from regions in the primate brain that served functions that were not in themselves linguistic. And he wishes to know: How much increase in complexity was involved in this recruitment, and was it credible without design? He suggests that Pinker and Bloom's concept of complexity does not capture the distinction between complexity and increase in complexity. And Lewontin (1990, p. 741) maintains that we simply do not know how much change in the brain really had to take place "to make linguistic competence". This 
question is not addressed directly either by Pinker and Bloom in their response to Lewontin's commentary.

Which brings us to the third distinction that is collapsed in Pinker and Bloom's concept of adaptive complexity: that between the adaptive properties and the complex properties of an object. In this connection, Pesetsky and Block (1990, p. 750) have pointed out in the BBS discussion that Pinker and Bloom's selectionist account of the evolution of language requires the adaptive properties and the complex properties of language to be the same. Pesetsky and Block's first point now is that this assumption can be falsified in both directions, since there is a mismatch of adaptive properties and complex properties.

On the one hand, they observe, the properties of language considered adaptive by Pinker and Bloom are not judged to be complex by generative linguists:

Their properties get scant mention in "linguistic practice" because they (unlike the structure of the human eye) are not complex enough to merit much discussion. (Pesetsky and Block, 1990, p. 750)

The properties referred to by Pesetsky and Block are those that have been exemplified in (4a)(4d) above.

On the other hand, Pesetsky and Block maintain, the properties considered complex by linguists are not adaptive in Pinker and Bloom's sense:

All or most of the complex properties of language fall in areas far removed from any currently adaptive function. (Pesetsky and Block, 1990, p. 750)

What compounds the problem of the mismatch of complex and adaptive properties, according to Pesetsky and Block, is that the complex properties discussed by linguists seem, despite their not being adaptive, to be deeply rooted in the human language faculty. These properties are, moreover, "detectable in any human language whose other properties do not inhibit the discovery of these facts". 
How then do Pinker and Bloom respond to Pesetsky and Block's point about the mismatch of adaptive properties and complex properties? They (1990, p. 765) do commend Pesetsky and Block - as well as Ridley, Sober, and Tooby and Cosmides - for having presented "lucid arguments ... about the central role of adaptation in evolution ...". But as far as specifics are concerned, their response to Pesetsky and Block's point is tangential at best. As an illustration of the "complexities" that linguists study, Pesetsky and Block offer the following example amongst others: linguists want to know why alongside passive nominals like the city's destruction by the enemy we do not find the city's sight by the enemy. And with reference to this example, they ask, -

Are the domains that linguists find complex also adaptive? What reproductive advantage is conferred on speakers because they do not fully accept the city's sight by the enemy? ... What function would be impaired if a speaker did accept the city's sight by the enemy? (We are ignoring the reproductive advantage to be gained by conforming with the rest of the local community. Such an advantage is independent of the complexity of the language that is shared.) (Pesetsky and Block, 1990, p. 751)

Pinker and Bloom's response to these questions by Pesetsky and Block reads as follows:

We don't need to determine "the reproductive advantage ... conferred on speakers because they do not fully accept the city's sight by the enemy" because this is a datum about a bit of behaviour, not a biological structure, and thus did not evolve itself; it's the language faculty, which gave rise to the judgement data, that evolved. (Pinker and Bloom, 1990, p. 771)

Pinker and Bloom's claim that the judgement in question is "a datum about a bit of behaviour, not about a biological structure" is puzzling. On the standard generativist construal of the import of linguistic judgements, the judgement in question is taken to be ultimately a datum about a feature of the language faculty: the feature that causes speakers to consistently judge the utterance not (fully) acceptable. Underlying this construal of linguistic judgements is the following ontology: 
(9a) (Intuitive) linguistic judgements are products of acts of language behaviour.

(9b) Acts of language behaviour are products of the use of, amongst other things, speakers' linguistic competence.

(9c) Speakers' linguistic competence is the product of the growth / maturation of (the initial state of) their language faculty.

In terms of this ontology, questions about linguistic judgements - such as the question being considered here - are questions about causal mechanisms forming part of speakers' linguistic competence and, ultimately, forming part of (the initial state of) their language faculty. What makes Pinker and Bloom's quoted response so puzzling is that they seem to realize this when they state that "it's the language faculty ... which gave rise to the judgement data". But, strangely, they do not draw the consequences of this position when responding to Pesetsky and Block's question about the reproductive advantage of speakers' judging the city's sight by the enemy unacceptable. That question clearly has to be understood as a question about the reproductive advantage of the underlying mechanism - which is something biological responsible for the judgement in question. It would be quite implausible to suggest that, in asking the quoted questions about the judgement under consideration, Pesetsky and Block wished to be understood in any other way. Which means that what Pinker and Bloom argue does not really address Pesetsky and Block's point about the non-adaptivity of the features of language judged complex by generative linguists. Nor do Pinker and Bloom address that point when they go on to observe that-

Pesetsky and Block, by focusing on what linguists find "worth studying", state that the complex features of grammar play no role in allowing people to communi-cate, to express an infinite number of meanings using a finite number of lexical items, and so on. This claim is surprising. Wasn't it Chomsky who characterized a grammar as defining a mapping between sounds and meanings, and who said that a speaker can "make use of an intricate structure of specific rules and guiding principles to convey his thoughts and feelings to others, arousing in them novel ideas and subtle perceptions and judgments?" Don't linguists study such things as X-bar theory, word order parameters, inflectional morphology, segmental phonology, prosody, and so on, 
that are implicated every time we open our mouths to speak?' (Pinker and Bloom, 1990, p. 771)

In terms of this line of argument, every feature of a grammar would, derivatively, have a function simply in virtue of being a part of a system that defines a mapping between sounds and meanings (with the exception of ad-hoc devices that merely present summaries of unexplained phenomena, as Pinker and Bloom (1990, p. 772) put it.) But if this were the case, how should one understand Pinker and Bloom's providing for the "ubiquity ... of arbitrary aspects of even the most obvious adaptations"? And why would they (1990, pp. 717-718) have to take the trouble to explain away certain functionless features of language as (part of) an inherent trade-off of utility within language? Or why would they (1990, p. 718) have to argue that arbitrariness is built into language? Derivatively assigning a function to what are believed to be functionless features of language, clearly cannot address Pesetsky and Block's point about the mismatch of complex properties and adaptive properties. ${ }^{20}$

There is a certain line of argument that Pinker and Bloom could adopt in an attempt to counter the criticism that their concept of "adaptive complexity" is not sensitive to the distinction between the adaptive properties of the language faculty and its complex properties. They could argue that the notion of complex properties did not make sense, grounding this contention in their view that-

(10) It is not complexity per se that is at issue, but complexity of design. (Pinker and Bloom, 1990, p. 767)

Adopting (10), one could first observe that Pesetsky and Block, in criticizing some of the substantive claims made by Pinker and Bloom in terms of their concept of "adaptive complexity", refer to the (non-)complexity of "properties", "structures", "problems", "domains" or "facts". The (non-)complexity of these kinds of entities, one could then contend, is not the same phenomenon as complexity of design. For a design to be complex, the argument could run, ("facts" about) its properties, structures and so on are not required to be complex as well. Complexity of design can arise from the way in which noncomplex properties or structures are interlinked. The thrust of this line of argument would be, then, 
that Pesetsky and Block (and others) base their criticisms of Pinker and Bloom's claims about complexity of design on data that are irrelevant. In responding to the criticisms in question Pinker and Bloom themselves, however, do not develop any such argument explicitly. Curiously, they (1990, p. 771) seem to follow Pesetsky and Block in talking of "the complex features of grammar" (where on the ground of consistency one could have expected them to talk of "the complexity of design" of grammar.) Thereby, they effectively destroy the basis of this line of argument.

As a constituent of selectionist condition (2b), Pinker and Bloom's concept of "complex adaptive design," in sum, is not sufficiently well constrained in the sense that it fails to offer a basis for drawing some fundamental distinctions. These include the distinction between various sources of complexity, the distinction between complexity and an increase in complexity and the distinction between complex properties and adaptive properties. In view of these flaws in its conceptual basis, condition (2b) cannot be applied in a non-arbitrary way to either assign or deny language or a part of it the evolutionary status of an adaptation that evolved by natural selection.

\section{Conclusion}

How much, then, does Pinker and Bloom's selectionist account contribute towards answering the question whether human language evolved by natural selection? In a nutshell: not as much as could have been expected from a "sophisticated" account. Their account may well be as sophisticated as various BBS commentators assert. But it is an instance of a conceptually less sophisticated kind of selectionist account of language evolution - one that fails to draw a principled distinction between-

(10a) the evolution of language, the evolution of the language faculty and the evolution of parts or features of (the) language (faculty),

(10b) dysfunctionality, nonuniqueness and functionlessness as properties of parts of (the) language (faculty), 
(10c) the design, complexity and adaptivity of (the) language (faculty) as a univocal object as opposed to the design, complexity and adaptivity of individual parts or features of (the) language (faculty),

(10d) complex features of (the) language (faculty) and adaptive features of (the) language (faculty), and

(10e) adaptive complexity and such other kinds of complexity as arbitrary complexity.

Selectionist accounts of a conceptually more sophisticated kind would place appropriate constraints on the content - and thereby the applicability - of the concepts involved in these distinctions. $^{21}$ In the absence of such constraints, it remains impossible to say with any confidence to what extent and in what respects language was "shaped" by natural selection.

\section{Acknowledgements}

I am grateful to Walter Winckler for making many improvements in the readability of this article. 


\section{NOTES}

1. Modern authors describe the complexity of specifically the vertebrate eye in a much more detailed way. See in this connection, for example, Pinker and Bloom (1990, p.709).

2. Darwin initially "freely confessed" that to suppose that an organ of such "extreme perfection and complication" as the eye could have been formed by natural selection "seems ... absurd in the highest possible degree". For an account of Darwin's views on the evolution of the eye and of how these views have been misrepresented by antievolutionists, see Gould (1994, p. 10), and Dawkins (1996).

3. See in this connection, for example, Brandon and Hornstein (1986), Hurford (1989, 1991, 1992), Pinker and Bloom (1990), Newmeyer (1998), Donald (1991, 1993, 1999), Dunbar (1993), Aiello and Dunbar (1993), Maynard Smith and Szathmáry (1995, pp. 290-293). For selectionist accounts of various aspects of speech and of some of the mechanisms involved in the production or perception of speech, see, for example, MacNeilage (1998a, b), Studdert-Kennedy (1998, 2000), Lindblom (1990, 1992, 1998).

4. Pinker and Bloom's selectionist account was published and discussed as a target article in the interdisciplinary journal Behavioral and Brain Sciences (=BBS), Vols. 13 (1990) and 17 (1994). This account is outlined in part in Pinker (1994, chap. 10, and 1995) and in Bloom $(1998,1999)$ as well.

5. These comments include the following: "In their remarkably well-written essay, based on a wealth of sources from many disciplines, Pinker and Bloom (P\&B) offer a novel and sophisticated version of adaptationism" (Piattelli-Palmarini, 1990, p. 752). "Pinker and Bloom $(\mathrm{P} \& \mathrm{~B})$ have defended a selectionist account of language. The thoroughness with which they have done so is most welcome. I applaud P\&B's account for its sophistication and persuasiveness" (Catania, 1990, p. 729). "The minor disagreements I have with Pinker and Bloom's (P\&B's) admirable target article are trivial and beneath mention..." (Ridley, 1990, p. 756). "That is why the target article is such a keen pleasure to read. $\mathrm{P} \& \mathrm{~B}$ have found their way through a briar patch of rhetorical obfuscation to an impeccable understanding of modern Darwinism. P\&B's central contention seems inescapable" (Tooby and Cosmides, 1990, p. 761). "Pinker and Bloom $(\mathrm{P} \& \mathrm{~B})$ have done us a service in refuting the widespread belief among generativists that 
language could not have evolved by natural selection" (Broadwell, 1990, pp. 728-729). "Pinker and Bloom's (P\&B's) target article is deeply satisfying and liberating" (Hurford, 1990, p. 736). "The authors are to be honored for a paper that goes a long way toward countering the intemperate anti-Darwinism that has become the mode in some cognitive science circles over the past decade" (Studdert-Kennedy, 1990, p. 758). "Because I find the general thrust of the Pinker and Bloom (P\&B) target article to be compelling, this commentary will be devoted to further exploring the consequences of their hypothesis that the language faculty was shaped by natural selection" (Newmeyer, 1990 p. 745).

6. In Behavioral and Brain Sciences, Pinker and Bloom's target article is followed by commentary by some thirty-three "peers" which, in turn, is followed by a response from Pinker and Bloom. The debate has continued outside BBS, as witness, for example, Botha (1997a, b, 1998a, b), Gould (1997a, b, c), Grantham and Nichols (1999), Jenkins (2000), Knight, Studdert-Kennedy and Hurford (2000), and Lightfoot (2000).

7. Scholars working on language evolution are on the whole less than precise in identifying the entity/entities whose evolution is at issue, as is shown by Botha (2000).

8. For a detailed discussion of some of the ontological problems arising from Pinker and Bloom's use of the expressions language, the language faculty etc., see Botha (1997a, pp. 252-259).

9. For Chomsky's characterization of the initial state of the language faculty, see Chomsky (1980, pp. 65, 187, 1981, pp. 34-35, 1987, pp. 34-35), Botha (1997a, p. 256). Chomsky (1986, pp. 24-26) also provides for an attained, stable, state of the language faculty. Embodying someone's knowledge of language, this state "grows" out of the initial state under the "triggering" and "shaping" influence of his/her linguistic experience as a child.

10. In what follows, I no longer put the expressions "parts", "features" and their loose synonyms in quotation marks. I do so purely for convenience; I do not mean to signal that these expressions are unproblematic in Pinker and Bloom's selectionist account of language evolution.

11. Various aspects of Pinker and Bloom's characterization of the function of language have been criticized in the BBS debate. On the whole, however, their response to these criticisms has been adequate, as is shown in Botha (1997b, pp. 320-322). 
12. Other examples of substantive universals furnished by Pinker and Bloom (1990, p. 713714) include phrase structure rules, rules of linear order, case affixes, auxiliaries, and mechanisms of complementation and control.

13. Piattelli-Palmarini (1990, p. 753) offers the following "simple situation" to concretize his point:

"John and Marcia are going to be married, and I want to assert now that one day, three months after their marriage (call it D day) John is going to discover that Marcia is pregnant on D day. Can I state this simple thought in a more compact, less cumbersome sentence?... It seems not...:

1. John will discover that Marcia is pregnant.

won't do, because (1) is also true if John will discover on D day that Marcia is pregnant now, at this very moment.

2. John will discover that Marcia will be pregnant. won't do either, because (2) is true also if, on D day, John will discover that Marcia will be pregnant at some time after D day. It is easy to see that other attempts are equally unsuccessful, even allowing ourselves to plainly ungrammatical constructions [sic]:

3. John will have discovered that Marcia (is) (was) (will be) (*will have been) (has been) pregnant." (Piattelli-Palmarini, 1990, p. 753)

14. "Spandrel" is a term taken over from architecture by Gould and Lewontin (1979) for denoting biological structures or traits that serve functions for which they were not originally designed.

15. Structure-dependency is a universal constraint on the class of possible grammatical rules. Structure-dependent rules refer to structural properties of constituents of sentences. Structure-independent rules, by contrast, refer only to the linear position of such constituents. What (the universal of) structure-dependency states is that language uses structure-dependent grammatical rules only. For an informal illustration of the nature of structure-dependent grammatical rules, see Chomsky (1988, pp. 41-46).

16. The Case Filter embodies the requirement that all overt NPs be assigned abstract case. For an illustration of the Case Filter, see Haegeman (1991, p. 141, 156).

17. Allen and Bekoff (1995, p. 617) illustrate these points with reference to the behaviour of a hare confronted by a fox. The hare's behaviour, it has been hypothesized, is to indicate 
to the fox that it has been detected. This hypothesis, in Allen and Bekoff's view, "is justified if it is reasonable to believe that bipedal standing by ancestral hares had this effect on ancestral foxes, and this effect was (partially) responsible for the transmission of this trait from ancestral hares to descendants". On their analysis, "A corresponding design claim about bipedal standing would ... require showing that this trait is a direct modification of some ancestral trait that was less efficient with respect to its effect on foxes".

18. This characterization of complexity is consonant with those offered by Williams and by Dawkins. On Dawkins's (1988) characterization a complex thing-

(a) is something that has a heterogeneous structure (p. 6);

(b) is something whose constituent parts are arranged in a way that is unlikely to have arisen by chance alone (p. 7);

(c) is something that is good for or at something (in virtue of having a particular internal structure) (p. 9).

19. Pinker and Bloom (1990, p. 718) base their ideas about the principle (or requirement) of parity on work by Liberman and Mattingly (1989). It states that any communication system requires a coding protocol that can be arbitrary as long as it is shared.

20. Responding to a letter by Pinker (1997) in The New York Review of Books, Gould (1997b, p. 57) observes that in the former letter Pinker fails to draw a distinction between "complex design" and "complex adaptive design": "Complex design forms a much broader category than adaptive design - and has many other potential evolutionary causes". In similar vein, Grantham and Nichols (1999, pp. 51 - 52) cite work by Kauffmann (1995) and Page and Mitchell (1990) which supports the view that "nonselective forces can create functional complexity". And Kirby (2000, p. 303) has argued that the emergence of (complex) compositional syntax can be explained without viewing it as an adaptation to natural selection pressures.

21. The kind of selectionist account proposed by Pinker and Bloom has non-conceptual limitations as well, as has been argued by, amongst others, Chomsky (1997), Gould (1997a, b, c), Jenkins (2000) and Lightfoot (2000). For an appraisal of the limitations that have been identified in the BBS debate, see Botha (1997a, b, 1998a, b). 


\section{REFERENCES}

Aiello, L.C., Dunbar, R.I.M., 1993. Neocortex size, group size, and the evolution of language. Current Anthropology 34, 184-193.

Allen, C., Bekoff, M., 1995. Biological function, adaptation, and natural design. Philosophy of Science 62, 609-622.

Bloom, P., 1998. Some issues in the evolution of language and thought. In: Cummins, M.C., Allen, C. (Eds.), The Evolution of Mind. Oxford University Press, New York, and Oxford, pp. 204-223.

Bloom, P., 1999. The evolution of certain novel human capacities. In: Corballis, M.C., Lea, S.E.G. (Eds.), The Descent of Mind. Psychological Perspectives on Hominid Evolution. University of Oxford Press, Oxford, pp. 295-310.

Botha, R.P., 1997a. Neo-Darwinian accounts of the evolution of language: 1. Questions about their explanatory focus. Language \& Communication 17, 249-267.

Botha, R.P., 1997b. Neo-Darwinian accounts of the evolution of language: 2. Questions about complex design. Language \& Communication 17, 319-340.

Botha, R.P., 1998a. Neo-Darwinian accounts of the evolution of language: 3. Questions about their evidential bases, logic and rhetoric. Language \& Communication 18, 17-46.

Botha, R.P., 1998b. Neo-Darwinian accounts of the evolution of language: 4. Questions about their comparative merit. Language \& Communication 18, 227-249.

Botha, R.P., 2000. Discussing the evolution of the assorted beasts called language. Language \& Communication 20, 149-160.

Brandon, R.N., Hornstein, N., 1986. From icons to symbols: some speculations on the origin of language. Biology and Philosophy 1, 169-189.

Broadwell, G.A., 1990. Linguistic function and linguistic evolution. Behavioral and Brain Sciences 13, 728-729.

Catania, A.C., 1990. What good is five percent of a language competence? Behavioral and Brain Sciences 13, 729-731.

Chomsky, N., 1980. Rules and Representations. Columbia University Press, New York.

Chomsky, N., 1981. Principles and parameters in syntactic theory. In: Hornstein, N.L., Lightfoot, D. (Eds.), Explanation in Linguistics: The Logical Problem of Language Acquisition. Longman, London and New York, pp. 32-75. 
Chomsky, N., 1986. Knowledge of Language: Its Nature, Origin and Use. Praeger, New York.

Chomsky, N., 1987. Language in a Psychological Setting. (=Sophia Linguistica 21). The Graduate School of Language and Linguistics, Tokyo.

Chomsky, N., 1988. Language and Problems of Knowledge. MIT Press, Cambridge MA.

Chomsky, N., 1997. The state of minimalist art. Lecture presented at the University of Cape Town, 29 May 1997.

Dawkins, R., 1988. The Blind Watchmaker. Penguin Books, London.

Dawkins, R., 1996. Climbing Mount Improbable. W.W. Norton \& Company, New York and London.

Darwin, C., 1859. The Origin of Species. Watts \& Co., London.

Donald, M., 1991. Origins of the Modern Mind: Three Stages in the Evolution of Culture and Cognition. MIT Press, Cambridge.

Donald, M.H., 1993. Origins of the modern mind. Behavioral and Brain Science 16, 737 791. [A target article followed by peer commentary and response by the author.]

Donald, M., 1999. Preconditions for the evolution of protolanguages. In Corballis, M.C., Lea, S.E.G. (Eds.), The Descent of Mind. Psychological Perspectives on Hominid Evolution. Oxford University Press, Oxford, pp. 138-154.

Dunbar, R.I.M., 1993. Coevolution of neocortical size, group size and language in humans. Behavioral and Brain Sciences 16, 681-735.

Gould, S.J., 1994. Common pathways of illumination. Natural History 12, 10-20.

Gould, S.J., 1997a. Darwinian fundamentalism. The New York Review of Books, 12 June, 1997, 34-37.

Gould, S.J., 1997b. Evolution: The pleasures of pluralism. The New York Review of Books, 26 June, 1997, 47-52.

Gould, S.J., 1997. Letter to The New York Review of Books, 9 October, 1997, 56-58.

Gould, S.J., Lewontin, R., 1979. The spandrels of San Marco and the Panglossian paradigm: A critique of the adaptationist programme. Proceedings of the Royal Society of London $205,281-288$.

Grantham, T., Nichols, S., 1999. Evolutionary psychology: Ultimate explanations and Panglossian predictions. In: Hardcastle, V.G. (Ed.), Where Biology Meets Psychology. Philosophical Essays. The MIT Press, Cambridge MA, pp. 47-66. 
Haegeman, L., 1991. Introduction to Government and Binding Theory. Basil Blackwell, Oxford.

Hornstein, N., 1990. Selecting grammars. Behavioral and Brain Sciences 13, 735-736.

Hurford, J.R., 1989. Biological evolution of the Saussurean sign as a component of the language acquisition device. Lingua 79, 187-222.

Hurford, J.R., 1990. Beyond the roadblock of linguistic evolution studies. Behavioral and Brain Sciences 13, 736-737.

Hurford, J.R., 1991. The evolution of the critical period for language acquisition. Cognition 40, 159-201.

Hurford, J.R., 1992. An approach to the phylogeny of the language faculty. In: Hawkins, J.A., Gell-Mann, M. (Eds.), The Evolution of Human Languages. Adison-Wesley Publishing Company, Redwood City, California, pp. 273-303.

Jenkins, L., 2000. Biolinguistics. Exploring the Biology of Language. Cambridge University Press, Cambridge.

Kauffmann, S., 1995. At Home in the Universe. The Search for Laws of Self-organization and Complexity. Oxford University Press, New York.

Knight, Studdert-Kennedy, Hurford, J.R., 2000. Language: A Darwinian adaptation. In: Knight, C., Studdert-Kennedy, M., Hurford, J.R. (Eds.), The Evolutionary Emergence of Language. Social Functions and the Origins of Linguistic Form. Cambridge University Press, Cambridge, pp. 1-15.

Kirby, S., 2000. Syntax without natural selection: How compositionality emerges from vocabulary in a population of learners. In: Knight, C., Studdert-Kennedy, M., Hurford, J.R. (Eds.), The Evolutionary Emergence of Language. Social Functions and the Origins of Linguistic Form. Cambridge University Press, Cambridge, pp. 303-323.

Lewontin, R., 1990. How much did the brain have to change for speech. Behavioral and Brain Sciences 13, 740-741.

Liberman, A., Mattingly, I., 1989. A specialization for speech perception. Science 243, 489496.

Lightfoot, D., 2000. The spandrels of the linguistic genotype. In: Knight, C., StuddertKennedy, M., Hurford, J.R. (Eds.), The Evolutionary Emergence of Language. Social Functions and the Origins of Linguistic Form. Cambridge University Press, Cambridge, pp. 231-247. 
Lindblom, B., 1990. Adaptive complexity in sound patterns. Behavioral and Brain Sciences $13,743-744$.

Lindblom, B., 1992. Phonological units as adaptive emergents of lexical development. In: Ferguson, C.A., Menn, L., Stoel-Gammon, C. (Eds.), Phonological Development: Models, Research, Implications. York Press, Timonium, MD, pp. 131-163.

Lindblom, B., 1998. Systemic constraints and adaptive change in the formation of sound structure. In: Hurford, J.R., Studdert-Kennedy, M., Knight, C. (Eds.), Approaches to the Evolution of Language. Social and Cognitive Bases. Cambridge University Press. Cambridge, pp. 242-264.

MacNeilage, P.F. 1998a. The frame/content theory of evolution of speech production. Behavioral and Brain Sciences 21, 499-546. [A target article followed by peer commentary and a response by the author.]

MacNeilage, P.F. 1998b. Evolution of the mechanism of language output: comparative neurobiology of vocal and manual communication. In: Hurford, J.R., Studdert-Kennedy, M., Knight, C. (Eds.), Approaches to the Evolution of Language. Social and Cognitive Bases. Cambridge University Press, Cambridge, pp. 222-241.

Maynard Smith, J., Szathmáry, E., 1995. The Major Transitions in Evolution. W.H. Freeman/Spektrum, Oxford.

Newmeyer, F.J., 1990. Natural selection and the autonomy of syntax. Behavioral and Brain Sciences 13, 745-746.

Newmeyer, F.J., 1998. On the supposed 'counterfactuality' of Universal Grammar: some evolutionary implications. In: Hurford, J., Studdert-Kennedy, M., Knight, C. (Eds.), Approaches to the Evolution of Language. Social and Cognitive Bases. Cambridge University Press, Cambridge pp. 305-319.

Ninio, A., 1990. The genome might as well store the entire language in the environment. Behavioral and Brain Sciences 13, 746-747.

Page, R., Mitchell, S., 1990. Self-organization and adaptation in insect societies. In: Fine, A. et al. (Eds.), PSA 1990, Vol. 2, Philosophy of Science Association, East Lansing MI, pp. 289-298.

Pesetsky, D., Block, N., 1990. Complexity and adaptation. Behavioral and Brain Sciences 13,750 . 
Piattelli-Palmarini, M., 1990. An ideological battle over modals and quantifiers. Behavioral and Brain Sciences 13, 752-754.

Pinker, S., 1994. The Language Instinct: How the Mind Creates Language. William Morrow and Company, Inc., New York.

Pinker, S., 1995. Language is a human instinct. In: Brockman, J. (Ed.), The Third Culture: Beyond the Scientific Revolution. Simon and Schuster, New York, pp. 223-236.

Pinker, S., Bloom, P., 1990. Natural language and natural selection. Behavioral and Brain Sciences 13, 707-727, 765-784.

Ridley, M., 1990. Arbitrariness is no argument against adaptation. Behavioral and Brain Sciences 13,756 .

Sober, E., 1990. Anatomizing the rhinoceros. Behavioral and Brain Sciences 13, 764-765.

Sperber, D., 1990. The evolution of the language faculty: a paradox and its solution. Behavioral and Brain Sciences 13, 756-758.

Studdert-Kennedy, M., 1990. This view of language. Behavioral and Brain Sciences 13, 758759.

Studdert-Kennedy, M., 1998. The particulate origins of language generativity: from syllable to gesture. In: Hurford, J.R., Studdert-Kennedy, M., Knight, C. (Eds.), Approaches to the Evolution of Language. Social and Cognitive Bases. Cambridge University Press, Cambridge, pp. 202-241.

Studdert-Kennedy, M., 2000. Evolutionary implications of the particulate principle: Imitation and the dissociation of phonetic form from semantic function. In: Knight, C., Studdert-Kennedy, M., Hurford, J.R. (Eds.). The Evolutionary Emergence of Language. Social Function and the Origins of Linguistic Form. Cambridge University Press, Cambridge, pp. 161-176.

Tooby, J., Cosmides, L., 1990. Toward an adaptationist psycholinguistics. Behavioral and Brain Sciences 13, 760-762. 